\title{
Identification of genes expressed by Cryptococcus gattii during iron deprivation
}

\author{
Daphine Ariadne Jesus de Paula ${ }^{1}$, Lívia Kmetzsch Rosa e Silva ${ }^{2}$, \\ Charley Christian Staats ${ }^{2}$, Marilene H. Vainstein ${ }^{2}$, Ana Lúcia Pinto Joanoni ${ }^{1}$, \\ Luciano Nakazato $^{1}$, Valéria Dutra ${ }^{1}$ \\ ${ }^{1}$ Universidade Federal de Mato Grosso, Cuiabá, MT, Brazil. \\ ${ }^{2}$ Centro de Biotecnologia, Universidade Federal do Rio Grande do Sul, Porto Alegre, RS, Brazil.
}

Submitted: April 26; Approved: December 13, 2013.

\begin{abstract}
Cryptococcus neoformans and C. gattii are pathogenic yeasts that cause life-threatening diseases in humans and animals. Iron is an essential nutrient for virtually every organism as it functions as a cofactor in numerous essential enzymatic reactions. In the literature, the competition for iron between microbes and mammalian hosts during infection is well documented. In this study, we used representational difference analysis (RDA) in order to gain a better understanding of how C. gattii responds to iron starvation. A total of 15 and 29 genes were identified as having altered expression levels due to iron depletion after $3 \mathrm{~h}$ and $12 \mathrm{~h}$, respectively. Of these, eight genes were identified in both libraries. The transcripts were related to many biological processes, such as cell cycle, ergosterol metabolism, cell wall organization, transportation, translation, cell respiration and the stress response. These data suggest a remodeling of $C$. gattii metabolism during conditions of iron deprivation.
\end{abstract}

Key words: Cryptococcus gattii, iron, representational difference analysis, yeast.

\section{Introduction}

The Cryptococcus neoformans species complex comprises basidiomycetous yeasts that cause life-threatening diseases in humans and animals. There are two main pathogenic species within the Cryptococcus genus, namely $C$. neoformans and C. gattii. C. neoformans var. grubii and $C$. neoformans var. neoformans have been isolated worldwide, and typically cause disease in hosts with impaired immunity. Cryptococcus gattii is found in tropical and subtropical climates and is frequently associated with the infection of immunocompetent hosts (Kwong-Chung and Bennett, 1992; Sorrell 2001). C. gattii emerged as an important pathogen when an outbreak of cryptococcosis occurred in 1999 on Vancouver Island, British Columbia, Canada, and is still ongoing (Byrnes et al., 2010; Kidd et al., 2004; Stephen et al., 2002), along with an outbreak of infections in otherwise healthy people and animals in western North America (Bartlett et al., 2008). C. gattii therefore continues to pose serious public health problems for immunocompromised and healthy individuals worldwide.
The documented virulence factors are common to both $C$. neoformans and $C$. gattii, and include production of a polysaccharide capsule; formation of the pigment melanin in the cell wall; growth at $37^{\circ} \mathrm{C}$; and secretion of enzymes such as phospholipase B and urease (Casadevall and Perfect, 1998).

Iron is an essential nutrient for virtually every organism because it participates as a cofactor in numerous essential enzymatic reactions involving the transfer of electrons. In the literature, the competition for iron between microbes and mammalian hosts during infection is well documented (Sutak et al., 2008). In mammalian hosts, the majority of iron is locked within iron-binding proteins, pathogens must therefore be equipped with competitive iron acquisition and uptake systems. C. neoformans possesses cell surface reductases that reduce ferric iron to its ferrous state (Cfo1), export reductants, such as 3-hydroxyanthranilic acid, and iron permease $(\mathrm{Cft} 1)$ for transport into the cytosol as ferric ion (Jacobson et al., 1998; Jung et al., 2008b, 2009; Nyhus et al., 1997, 1999). In addition, for C. neoformans, many studies have described genes related to iron regulation, in- 
cluding Cryptococcus iron regulator 1 (CIR1) (Jung et al., 2006) and HAPX, genes that control the expression of iron-dependent genes (Jung et al., 2010).

In C. gattii, little is known about iron metabolism and its implication in virulence. Crestani et al. (2012) recently carried out a study of the proteomic profile of this yeast under iron-deplete and iron-replete conditions, and observed a similar regulation of metabolic proteins in both the pathogenic yeasts, $C$. gattii and $C$. neoformans. However, certain proteins related to iron homeostasis in $C$. neoformans were not identified. Silva et al. (2011) performed a genome comparative analysis of genes related to micronutrient metabolism in $C$. neoformans and C. gattii; these authors reported differences between the yeasts in expression of genes related to iron homeostasis, such as metalloreductase and ferroxidase homologs. Ma et al. (2010) proposed that the hypervirulence exhibited by $C$. gattii is associated with its mitochondrial gene expression.

Herein, we were interested in gaining an understanding of the mechanisms involved in iron regulation in $C$. gattii. In order to investigate the adaptive cellular responses when host-iron availability to pathogenic microorganisms is reduced, we attempted to identify the differential gene expression profile of the C. gattii reference strain R265 under conditions of iron deprivation, using representational difference analysis (RDA).

\section{Materials and Methods}

\section{Strain, culture conditions and RNA extraction}

The $C$. gattii strain R265 was used for the RDA experiments and gene expression analysis. For construction of the RDA libraries, R265 was routinely grown in Yeast Peptone Dextrose (YPD) broth (yeast extract 1\%, peptone $1 \%$ and glucose $2 \%$ ) prior to cultivation in medium containing low levels of iron (limited-iron medium (LIM), according to Jacobson et al. (1998) and an iron-repleted medium (LIM+Fe, with the addition of $100 \mu \mathrm{M}$ FeHEDTA, Sigma Chemical Co., St Louis, MO) for $24 \mathrm{~h}$. To evaluate the effects of iron, $10^{6}$ cells $/ \mathrm{mL}$ of yeast were transferred to $50 \mathrm{~mL}$ of LIM or LIM-Fe. Cells were grown for two distinct periods of time ( $3 \mathrm{~h}$ or $12 \mathrm{~h}$ ) in LIM or LIM-Fe at $37^{\circ} \mathrm{C}$. Salts of polyvalent metals were dissolved in water treated with Chelex-100 (Bio-Rad) and filter sterilized. All glassware was soaked in Citranox acid detergent overnight and rinsed with distilled, deionized water before use with LIM.

Cells were harvested by centrifugation and immediately frozen in liquid nitrogen prior to RNA extraction. Total RNA was isolated using the RNeasy mini kit (Qiagen, Hilden, Germany), and cDNA was synthesized using the SMART PCR synthesis kit (CLONTECH Laboratories, Palo Alto, CA). First-strand cDNA synthesis was performed with reverse transcriptase (RT M-MLV, Invitrogen, Carlsbad, CA) from $500 \mathrm{ng}$ of total RNA. An aliquot of $5 \mu \mathrm{L}$ of first-strand cDNA was used as the template for second-strand synthesis.

\section{Representational difference analysis}

RDA was performed according to the protocol previously described by Dutra et al. (2004). Subtracted libraries were constructed using cDNA from $C$. gattii grown for $3 \mathrm{~h}$ and $12 \mathrm{~h}$ in a low-level iron medium (LIM) as the "tester" and cDNA from $C$. gattii grown for $3 \mathrm{~h}$ and $12 \mathrm{~h}$ in iron-replete medium (LIM+Fe) as the "driver". All cultures were grown at $37{ }^{\circ} \mathrm{C}$ with shaking. A double-stranded cDNA sample from each experimental condition was digested with Sau3AI (Sigma-Aldrich, St Louis, MO, USA) and resulting products were purified using the illustra GFX PCR DNA and gel band purification kit (GE Healthcare,Chalfont St Giles, England). The RBam24/12 adapters were ligated to the digested cDNA in order to be used as a tester. The first differential product (Dp1) was obtained by hybridization $\left(20 \mathrm{~h}\right.$ at $\left.67^{\circ} \mathrm{C}\right)$ of the driver and cDNA mixed at a 10:1 ratio, followed by PCR amplification with an RBam24 primer. In order to generate the second (Dp2) and third (Dp3) differential products, NBam and JBam adapters were ligated to the tester in each round of subtractive hybridization and the driver/tester ratio was increased to $100: 1$ and $1000: 1$, respectively. The oligonucleotides used for the RDA are listed in Table S1.

\section{Cloning and bioinformatics analysis of the RDA products}

The final RDA products (Dp3) were blunted with a Klenow DNA polymerase I fragment (Invitrogen) and phosphorylated with T4 polynucleotide kinase (Invitrogen). Fragments were ligated to a SmaI-digested and dephosphorylated pUC18 vector. Escherichia coli strain XL1-Blue-competent cells were transformed with the ligation products, and plasmid DNA was prepared from selected clones. Cloned inserts were sequenced using the DYEnamic ET Dye Terminator Cycle sequencing kit for the MegaBACE DNA analysis system (GE). Sequence quality was analyzed and the contig assembly was constructed using the Staden Package Software. Resulting sequences were compared to the Broad Institute Database (http://www.broadinstitute.org). Sequences returning matches with an E-value $\leq-10$ were annotated and classified based on their putative molecular function and/or biological process using the Gene Ontology classification system. Searches for well-conserved functional motifs were performed using the NCBI - conserved domain database (CDD).

\section{Quantitative real-time RT-PCR}

Primers for real-time RT-qPCR analysis were designed using Oligo Explorer 1.1.0 and are listed in Table S1. The predicted product length varied between $150 \mathrm{bp}$ and $200 \mathrm{bp}$. Real-time RT-qPCR was performed us- 
ing a StepOne ${ }^{\mathrm{TM}}$ Real-Time PCR System (Applied Biosystems). Reactions were composed of Platinum SYBR Green qPCR Supermix (Invitrogen), using 5 pmol of each primer, $2 \mu \mathrm{L}$ of template at a final volume of $25 \mu \mathrm{L}$. The PCR thermal cycling conditions were as follows: an initial step at $95^{\circ} \mathrm{C}$ for $5 \mathrm{~min}$, followed by 40 cycles at $95^{\circ} \mathrm{C}$ for $15 \mathrm{~s}$, and $60^{\circ} \mathrm{C}$ for $30 \mathrm{~s}$. Melting curve analyses were performed at the end of the reaction to confirm single PCR products. PCR reactions were monitored, and relative gene expression was quantified based on the $2^{-\Delta \Delta C T}$ method (Livak and Schmittgen, 2001). To attest the yeast iron-depleted conditions, the Hap proteins (HapX), transcription factor (Cir), iron permease (Cft1) and ferroxidase (Cfo1) targets were used in RT-qPCR experiments (Table S1). The housekeeping gene, actin (act), was used for normalization. All experiments were carried out using two independent cultures, and each cDNA sample was analyzed in triplicate for each target gene, as well as in triplicate for the housekeeping gene.

\section{Results}

A total of 389 and 442 high quality sequenced cDNA clones were obtained after $3 \mathrm{~h}$ and $12 \mathrm{~h} \mathrm{RDA}$, respectively. Through the RDA methodology, we found a total of 36 genes with differential RNA levels, where 15 genes were differentially expressed at $3 \mathrm{~h}$, and 29 genes were differentially expressed at $12 \mathrm{~h}$; of these, eight genes were identified in both libraries. Functional profiling of these genes using the Gene Ontology classification revealed transcripts 10 and 13 as being the main groups for the libraries (Tables 1 and 2). These transcripts were related to many different biological processes. We confirmed, by the RTqPCR technique, that the upregulated transcripts encoded for c-4 methyl sterol oxidase, alpha tubulin, polyadenylate-binding protein, transcriptional activator, vacuolar membrane protein, and Rds 1 in the $3 \mathrm{~h}$ library (Table 1 ). Regarding the transcripts obtained from the $12 \mathrm{~h}$ library, c-4 methyl sterol oxidase, ubiquitin-protein ligase, transporters, diacylglycerol cholinephosphotransferase, heat shock protein 90, Rds1, polyadenylate-binding protein, glucosidase, alpha tubulin and nucleus protein were all upregulated (Table 2).

As we found some conserved hypothetical proteins in the present study, we performed searches in the NCBI Conserved Domains Database (CDD) in order to find the presence of domains that may provide insights into the function of these proteins. The hypothetical protein with the GenBank accession number XP_570947.1 has a ZZ-type zinc finger domain, thought to be involved in proteinprotein interactions. The hypothetical protein XP_776919.1 has an inositol monophosphatase (IMPase) domain and other related domains. IMPase dephosphorylates inositol phosphate to generate inositol, which may be recycled into inositol lipids; in eukaryotes, IMPase plays a vital role in intracellular signaling.

We also found a dual specificity phosphatase catalytic domain (Ser/Thr and Tyr protein phosphatase) at the hypothetical XP_570177.1. These are tyrosine-specific protein phosphatases that catalyze the removal of a phosphate group attached to a tyrosine residue using a cysteinyl-phosphate enzyme intermediate. These enzymes are key regulatory components in signal transduction pathways (such as the MAP kinase pathway), cell cycle control and the control of cell growth, proliferation, differentiation and transformation.

\section{Discussion}

We describe an application of the RDA methodology in the search for genes potentially relevant in the pathogenesis of the human pathogenic microorganism C. gattii. This technique was applied to C. neoformans and C. gattii to detect new genes, possibly involved in disease pathogenesis (Goulart et al., 2001; Rosa e Silva et al., 2008).

The cellular machinery involved in iron metabolism has been more clearly demonstrated for $C$. neoformans (Jacobson et al., 1998; Jung et al., 2006, 2008a, 2008b, 2009, 2010; Jung and Kronstad, 2011; Lian et al., 2005) compared to C. gattii, where only a proteomic profile by Crestani et al. (2012) and an in silico analysis performed by Silva et al. (2011) have been described.

Cryptococcus neoformans uses several transport systems to acquire iron from the environment. Both high- and low-affinity iron uptake activities, mediated by cell surface reductases, have been described, namely the permease/ferroxidase complex for iron uptake, iron sensing/regulation proteins and siderophore utilization (Jacobson et al., 1998). Our RDA study revealed some different results in gene function compared with previous studies in C. neoformans. However, the studies mentioned above have been based on different approaches for evaluating gene expression; RDA methodology uses an alternative strategy and is a sensitivity tool for the isolation of rare differentially expressed transcripts (Pastorian et al., 2000). In this way, it was possible to identify transcripts representing only $1 \%$ of the mRNA population of a cell (Sugita and Sugiura, 1994). Due the relatively abundant expression of genes such as reductases and the permease/ferroxidase complex under iron deprivation conditions, it is possible that the technique was not able to identify these genes.

We found an alteration in the transcript 5-aminolevulinate synthase; this gene was differentially expressed in the $3 \mathrm{~h}$ library. However, despite being identified in the $12 \mathrm{~h}$ library using the RDA technique, it was not subsequently confirmed by RT-qPCR. The enzyme 5-aminolevulinate synthase catalyzes the first step in the heme biosynthetic pathway, with many transcripts encoding components of respiratory cytochromes, which contain 
Table 1 - Summary of the computational analysis a of the transcripts obtained from C. gattii grown in a low iron medium for $3 \mathrm{~h}$ at $37^{\circ} \mathrm{C}$

\begin{tabular}{|c|c|c|c|c|}
\hline Biological process & E value ${ }^{\mathrm{b}}$ & Access number (Genbank $)^{c}$ & Frequency (number of clones) ${ }^{\mathrm{d}}$ & Fold-change \\
\hline \multicolumn{5}{|l|}{ Ergosterol metabolism } \\
\hline C-4 methyl sterol oxidase & $1 \mathrm{E}-115$ & XP_569528.1 & 93 & 1.30 \\
\hline \multicolumn{5}{|l|}{ Cell cycle } \\
\hline alpha tubulin & $2 \mathrm{E}-70$ & XP_568869.1 & 162 & 1.60 \\
\hline g1/s-specific cyclin pcl1 (cyclin hes26) & $9 \mathrm{E}-22$ & XP_571897.1 & 11 & 0.91 \\
\hline MMS2 & $9 \mathrm{E}-16$ & XP_567564.1 & 04 & 0.81 \\
\hline \multicolumn{5}{|l|}{ Translation } \\
\hline polyadenylate-binding protein & $3 \mathrm{E}-34$ & XP_572834.1 & 73 & 1.18 \\
\hline \multicolumn{5}{|l|}{ Cell wall organization } \\
\hline endoglucanase E-4 precursor & $6 \mathrm{E}-73$ & XP_572272.1 & 17 & 0.88 \\
\hline \multicolumn{5}{|l|}{ Secretion and vesicle trafficking } \\
\hline vacuolar membrane protein & $5 \mathrm{E}-04$ & XP_569704.1 & 06 & 1.7 \\
\hline ARF small monomeric GTPase & $1 \mathrm{E}-10$ & XP_572032.1 & 01 & 0.81 \\
\hline \multicolumn{5}{|l|}{ Cellular respiration } \\
\hline 5-aminolevulinate synthase & $9 \mathrm{E}-70$ & XP_569249.1 & 04 & 1.1 \\
\hline \multicolumn{5}{|l|}{ Stress response } \\
\hline Rds1 protein & $8 \mathrm{E}-11$ & XP_568514.1 & 01 & 2.0 \\
\hline \multicolumn{5}{|l|}{ Transcription } \\
\hline transcriptional activator & $1 \mathrm{E}-34$ & XP_566547.1 & 01 & 1.3 \\
\hline \multicolumn{5}{|l|}{ Others } \\
\hline Metallochaperone & 9E-09 & XP_572504.1 & 05 & 0.86 \\
\hline minor histocompatibility antigen $\mathrm{h} 13$ & $9 \mathrm{E}-32$ & XP_572261.1 & 09 & 0.70 \\
\hline \multicolumn{5}{|l|}{ Hypothetical proteins } \\
\hline hypothetical protein CNF04510 & $1 \mathrm{E}-18$ & XP_571639.1 & 01 & 1.35 \\
\hline hypothetical protein CNJ02890 & $8 \mathrm{E}-18$ & XP_567569.1 & 01 & 1.52 \\
\hline \multicolumn{5}{|l|}{ Control Iron genes ${ }^{\mathrm{e}}$} \\
\hline high-affinity iron permease & & AFR98470.1 & & 15.41 \\
\hline Multicopper oxidase & & AFR98469.1 & & 17.45 \\
\hline Ion regulator 1 & & AFR97352.1 & & 1.19 \\
\hline bZIP transcription factor & & AFR94904.1 & & 8.21 \\
\hline
\end{tabular}

${ }^{a}$ Sequence quality was analyzed and contig assembly was constructed by using the Staden Package Software. Resulting sequences were compared to the Genbank database using the BLASTX program.

${ }^{b} \mathrm{E}$ value according to the information from BLASTX searches of the non-redundant database at NCBI.

${ }^{\mathrm{c}}$ Accession number of the gene products in the GenBank database.

${ }^{\mathrm{d}}$ Frequency represents the number of clones found in a total of 389 high quality sequenced cDNA clones.

${ }^{\mathrm{e}} \mathrm{Genes}$ used to validate iron deprivation conditions represented by reductive, high affinity iron transport and transcriptional factors).

several heme cofactors and some heme biosynthetic genes, and are down-regulated during iron deficiency (ShakouryElizeh et al., 2004, 2010). Transcriptional profiles of genes encoding components of respiratory cytochromes, are also influenced by the availability of iron (Pouliot et al., 2010). Under conditions of iron deficiency, the yeast activates the expression of proteins that lead to the degradation of mRNAs encoding proteins that function in iron-dependent pathways, thereby reducing the amount of iron required by these pathways (Sanguinetti et al., 2006). Perhaps this explains the differential expression evident at $3 \mathrm{~h}$ but not upon prolonged exposure to iron deprivation as observed in the $12 \mathrm{~h}$ library.

Genes controlling cell cycle, such as g1/s-specific cyclin pcl1 (cyclin hes26), were found in this study. Cyclin expression can fluctuate according to the stage of infection and it is suppressed at distinct stages in the process (García-Muse et al., 2004), and a similar scenario might take place in C. gattii. We observed that iron deficiency influenced the expression of these genes and, along with the reasons already mentioned, changes in the concentration of the ion might be another factor that could explain the reduction in the transcription of cell cycle-associated genes. In $C$. 
Table 2 - Summary of computational analysis ${ }^{\text {a }}$ of the transcripts obtained from $C$. gattii grown in low iron medium for 12 h at $37{ }^{\circ} \mathrm{C}$.

\begin{tabular}{|c|c|c|c|c|}
\hline Annotation & Ev value $^{\mathrm{b}}$ & Access number $(\text { Genbank })^{c}$ & Frequency (number of clones) ${ }^{\mathrm{d}}$ & Fold-change \\
\hline \multicolumn{5}{|l|}{ Ergosterol metabolism } \\
\hline C-4 methyl sterol oxidase & $2 \mathrm{E}-116$ & XP_569528.1 & 194 & 2.02 \\
\hline \multicolumn{5}{|l|}{ Protein catabolism } \\
\hline ubiquitin-protein ligase & $2 \mathrm{E}-37$ & XP_572505.1 & 11 & 1.40 \\
\hline \multicolumn{5}{|l|}{ Cellular respiration } \\
\hline mitochondrion protein & $7 \mathrm{E}-22$ & XP_571658.1 & 13 & 1.30 \\
\hline 5-aminolevulinate synthase & 7E-106 & XP_569249.1 & 09 & 0.52 \\
\hline \multicolumn{5}{|l|}{ Lipid metabolism } \\
\hline Delta-12 fatty acid desaturase & $2 \mathrm{E}-37$ & XP_570226.1 & 01 & 0.65 \\
\hline \multicolumn{5}{|l|}{ Transporters } \\
\hline $\mathrm{ABC}$ transporter & $5 \mathrm{E}-28$ & XP_568169.1 & 02 & 2.42 \\
\hline inorganic phosphate transporter & $1 \mathrm{E}-90$ & XP_568544.1 & 03 & 1.20 \\
\hline mRNA export factor elf1 & $9 \mathrm{E}-66$ & XP_566522.1 & 01 & 1.90 \\
\hline \multicolumn{5}{|l|}{ Cell wall or membrane organization } \\
\hline diacylglycerol cholinephosphotransferase & $1 \mathrm{E}-71$ & XP_571616.1 & 21 & 2.60 \\
\hline \multicolumn{5}{|l|}{ Stress response } \\
\hline Heat shock protein 90 & $7 \mathrm{E}-39$ & XM_568451.1 & 01 & 2.10 \\
\hline Rds1 protein & $1 \mathrm{E}-05$ & XP_568514.1 & 08 & 5.70 \\
\hline \multicolumn{5}{|l|}{ Translation } \\
\hline polyadenylate-binding protein & $4 \mathrm{E}-22$ & XP_572834.1 & 04 & 1.35 \\
\hline ribosomal protein L1 & $3 \mathrm{E}-48$ & XP_569608.1 & 01 & 0.85 \\
\hline \multicolumn{5}{|l|}{ Carbohydrate metabolism } \\
\hline Glucosidase & $2 \mathrm{E}-24$ & XP_570389.1 & 02 & 1.90 \\
\hline \multicolumn{5}{|l|}{ Cell cycle } \\
\hline g1/s-specific cyclin pcl1 (cyclin hcs26) & $7 \mathrm{E}-29$ & XP_571897.1 & 01 & 0.60 \\
\hline alpha tubulin & $2 \mathrm{E}-57$ & XP_568869.1 & 02 & 1.20 \\
\hline \multicolumn{5}{|l|}{ Nucleotide metabolism } \\
\hline guanosine-diphosphatase & $2 \mathrm{E}-86$ & XP_568971.1 & 02 & 0.75 \\
\hline \multicolumn{5}{|l|}{ Others } \\
\hline minor histocompatibility antigen h13 & $5 \mathrm{E}-34$ & XP_572261.1 & 01 & 0.80 \\
\hline nucleus protein & $1 \mathrm{E}-28$ & XP_567927.1 & 11 & 1.0 \\
\hline \multicolumn{5}{|l|}{ Hypothetical proteins } \\
\hline hypothetical protein & $2 \mathrm{E}-24$ & XP_571639.1 & 7 & 0.71 \\
\hline hypothetical protein CNBM2310 & $1 \mathrm{E}-60$ & XP_772074.1 & 80 & 2.44 \\
\hline hypothetical protein $\mathrm{CNBH} 2900$ & $3 \mathrm{E}-42$ & XP_773838.1 & 02 & 0.87 \\
\hline hypothetical protein $\mathrm{CNBC} 2910$ & $2 \mathrm{E}-23$ & XP_776800.1 & 01 & 0.30 \\
\hline hypothetical protein & $2 \mathrm{E}-36$ & XP_570947.1 & 01 & - \\
\hline hypothetical protein $\mathrm{CNBC} 4100$ & $6 \mathrm{E}-23$ & XP_776919.1 & 01 & 1.85 \\
\hline hypothetical protein & $4 \mathrm{E}-18$ & XP_570177. 1 & 01 & 1.50 \\
\hline hypothetical protein CNBM0150 & $4 \mathrm{E}-40$ & XP_772247.1 & 04 & - \\
\hline hypothetical protein CNM02470 & $5 \mathrm{E}-108$ & XP_568428.1 & 45 & - \\
\hline hypothetical protein CNBM0150 & $9 \mathrm{E}-33$ & XP_772247.1 & 12 & - \\
\hline \multicolumn{5}{|l|}{ Control Iron genes ${ }^{\mathrm{e}}$} \\
\hline high-affinity iron permease CaFTR1 & & AFR98470.1 & & 22.15 \\
\hline Multicopper oxidase & & AFR98469.1 & & 11.77 \\
\hline Ion regulator 1 & & AFR97352.1 & & 0.50 \\
\hline bZIP transcription factor & & AFR94904.1 & & 8.08 \\
\hline
\end{tabular}

a Sequence quality was analyzed using the Phred Program, and contig assembly was performed by using the Staden Package Software. Resulting sequences were compared to the Genbank database using the BLASTX program.

${ }^{b} \mathrm{E}$ value according to information from BLASTX searches of the non-redundant database at NCBI.

${ }^{\mathrm{c}}$ Accession number of the gene products in the GenBank database.

${ }^{\mathrm{d}}$ Frequency represents the number of clones found in a total of 442 high quality sequenced cDNA clones.

${ }^{\mathrm{e}} \mathrm{Genes}$ used to validate iron deprivation conditions represented by reductive, high affinity iron transport and transcriptional factors. 
gattii, a pattern of alterations in expression of genes related to the cell cycle and the organization of cellular organelles has been described for the specifically strain R265 (Ngamskulrungroj et al., 2011).

A slight regulation was demonstrated for an ironregulated transcript identified in our study, which was shown to be a mitochondrial protein. It was also reported that iron availability affects mitochondrial-related genes in C. neoformans and proteins in C. gattii (Crestani et al., 2012; Lian et al., 2005). Ma et al. (2009) demonstrated a potential role of mitochondria in regulating virulence in the Vancouver Island Outbreak (VIO) lineage of C. gattii. The authors showed that $C$. gattii strains from within the VIO lineage exhibited enhanced intracellular proliferation within host macrophages and identified mitochondrial gene expression as the major hallmark of virulence in this species.

We found a novel transcriptional activator belonging to the GATA zinc finger gene family (XP 566547.1) that was only upregulated in the $3 \mathrm{~h}$ library (1.3-fold). According to Jung et al. (2006, 2008a), Cir1, a GATA-type transcription factor, is not influenced by iron, although Cir1 mediates nearly all of the transcriptional responses to iron in C. neoformans. Cir1 regulates the expression of genes required for the utilization of essential metals such as iron and copper, the transcription of iron transport and homeostasis functions, and influences the main virulence factors (Jung et al., 2006). cirl mutants displayed transcriptional unresponsiveness to iron deprivation, poor growth at $37^{\circ} \mathrm{C}$, loss of capsule formation, altered melanin production and were completely avirulent in a mouse model of cryptococcosis. Recently, Jung et al. (2010) described the role of HAPX genes in iron utilization and virulence in C. neoformans. Hap proteins, and specifically $\operatorname{HapX}$, can regulate the expression of siderophore transporters and, in addition, can also positively regulate the expression of the CIR 1 transcript. Here we find a novel transcriptional activator influenced by iron, but further studies must be carried out in order to determine how, as well as which genes this activator can regulate in response to iron deprivation.

In C. neoformans, $\mathrm{ABC}$ transporters are up-regulated in cells internalized by murine macrophages (Jung et al., 2006), and ATP-binding cassette transporter-encoding gene antifungal resistance 1 (AFR1) enhances the virulence of $C$. neoformans and its ability to survive within macrophages (Sanguinetti et al., 2006). In this study, the upregulation of this transporter can be related to the stress response involved in the prolonged exposure time to iron deprivation conditions, as the gene only shows a different expression level in the $12 \mathrm{~h}$ condition. Perhaps, these iron deprivation conditions stimulate $\mathrm{ABC}$ transporters to mobilize stored iron. In $S$. cerevisiae, Atm $1 \mathrm{p}$ is an ABC transporter located in the mitochondrial inner membrane that exports sulfur and possibly iron from the mitochondria to the cytosol (Chloupková et al., 2004). Analysis in S. pombe identified an abc3+ (ABCC subfamily of ATP-binding cassette (ABC) transporters) (Paumi et al., 2008) that was transcriptionally activated in response to iron deprivation. In response to iron deficiency (Pouliot et al., 2010), abc3+ could serve to transport iron stored from the vacuole to the cytoplasm.

The RDA data revealed a connection between iron deprivation, ergosterol metabolism, lipid metabolism and cell wall and membrane organization. C-4 methyl sterol oxidase was up-regulated at $3 \mathrm{~h}$ and $12 \mathrm{~h}$ in response to iron deprivation. Biosynthesis of sterol and of unsaturated fatty acids are essential processes that depend on both oxygen and iron. Philpott and Protchenko (2008) demonstrated that genes related to sterol biosynthesis (ERG genes) increased upon iron depletion. The authors suggest that the activity of iron-requiring proteins in these pathways is reduced, thereby limiting the levels of reaction products and resulting in decreased feedback inhibition and increased gene transcription. The connection between oxygen-sensing, ergosterol synthesis and iron uptake in C. neoformans may be due to the deletion of the regulatory gene $S R E 1$, which downregulates genes required for ergosterol biosynthesis and for iron and copper transport (Chang et al., 2007). The mutants cirl and cftl increased sensitivity to an inhibitor of ergosterol biosynthesis.

Diacylglycerol cholinephosphotransferase, a gene related to cell wall and membrane organization, was found to be induced under conditions of iron deprivation. In response to stress, cell remodeling via sterol metabolism and fatty acid biosynthesis has been described (Puig et al., 2005). This gene is regulated by temperature in $C$. neoformans (Rosa e Silva et al., 2008), and our results suggest that not only temperature, but also under iron deprivation conditions, remodeling of cell membranes may occur.

In summary, we found some novel genes related to iron homeostasis. However, further characterization of these genes through in vivo assays (gene knockout) is necessary in order to establish how these genes function, and how their regulation of iron levels influences $C$. gattii pathogenicity. Next Generation Sequencing (NGS) technologies are an alternative for qualitatively and quantitatively profiling the complete set of transcripts in order to fully understand the $C$. gattii response to iron and other micronutrient deficiencies.

\section{Acknowledgments}

This work was supported by grants from the Conselho Nacional de Desenvolvimento Científico e Tecnológico(CNPq), Coordenação de Aperfeiçoamento de Pessoal de Nível Superior (CAPES) and Fundação de Amparo à Pesquisa do Estado de Mato Grosso (FAPEMAT). 


\section{References}

Bartlett KH, Kidd SE, Kronstad JW (2008) The emergence of Cryptococcus gattii in British Columbia and the Pacific Northwest. Curr Infect Dis Rep 10:58-65.

Byrnes EJ, Li W, Lewit Y, Ma H, Voelz K, Ren P, Carter DA, Chaturvedi V, Bildfell RJ, May RC, Heitman J (2010) Emergence and pathogenicity of highly virulent Cryptococcus gattii genotypes in the northwest United States. PLoS Pathog 6:e1000850.

Casadevall A, Perfect JR (1998) Cryptococcus neoformans. American Society fot Microbiology, Washington, DC.

Chang YC, Bien CM, Lee H, Espenshade PJ, Kwon-Chung KJ (2007) Srelp, a regulator of oxygen sensing and sterol homeostasis, is required for virulence in Cryptococcus neoformans. Mol Microbiol 64:614-629.

Chloupková M, Reaves SK, LeBard LM, Koeller DM (2004) The mitochondrial ABC transporter Atm1p functions as a homodimer. FEBS Lett 569:65-69.

Crestani J, Carvalho PC, Han X, Seixas A, Broetto L, Fischer JeS, Staats CC, Schrank A, Yates JR, Vainstein MH (2012) Proteomic Profiling of the Influence of Iron Availability on Cryptococcus gattii. J Proteome Res 11:189-205.

Dutra V, Nakazato L, Broetto L, Silveira Schrank I, Henning Vainstein M, Schrank A (2004) Application of representational difference analysis to identify sequence tags expressed by Metarhizium anisopliae during the infection process of the tick Boophilus microplus cuticle. Res Microbiol 155:245-251.

García-Muse T, Steinberg G, Perez-Martín J (2004) Characterization of B-type cyclins in the smut fungus Ustilago maydis: roles in morphogenesis and pathogenicity. J Cell Sci 117:487-506.

Goulart L, Rosa e Silva LK, Chiapello L, Silveira C, Crestani J, Masih D, Vainstein MH (2010) Cryptococcus neoformans and Cryptococcus gattii genes preferentially expressed during rat macrophage infection. Med Mycol 48:932-941.

Jacobson ES, Goodner AP, Nyhus KJ (1998) Ferrous iron uptake in Cryptococcus neoformans. Infect Immun 66:4169-4175.

Jung WH, Sham A, White R, Kronstad JW (2006) Iron regulation of the major virulence factors in the AIDS-associated pathogen Cryptococcus neoformans. PLoS Biol 4:e410.

Jung WH, Kronstad JW (2008) Iron and fungal pathogenesis: a case study with Cryptococcus neoformans. Cell Microbiol 10:277-284.

Jung WH, Sham A, Lian T, Singh A, Kosman DJ, Kronstad JW (2008) Iron source preference and regulation of iron uptake in Cryptococcus neoformans. PLoS Pathog 4:e45b.

Jung WH, Hu G, Kuo W, Kronstad JW (2009) Role of ferroxidases in iron uptake and virulence of Cryptococcus neoformans. Eukaryot Cell 8:1511-1520.

Jung WH, Saikia S, Hu G, Wang J, Fung CK, D'Souza C, White R, Kronstad JW (2010) HapX positively and negatively regulates the transcriptional response to iron deprivation in Cryptococcus neoformans. PLoS Pathog 6:e1001209.

Jung WH, Kronstad JW (2011) The iron-responsive, GATA-type transcription factor Cir1 influences mating in Cryptococcus neoformans. Mol Cells 31:73-77.

Kidd SE, Hagen F, Tscharke RL, Huynh M, Bartlett KH, Fyfe M, Macdougall L, Boekhout T, Kwon-Chung KJ, Meyer W (2004) A rare genotype of Cryptococcus gattii caused the cryptococcosis outbreak on Vancouver Island (British Co- lumbia, Canada). Proc Natl Acad Sci USA 101:1725817263.

Kwong-Chung K, Bennett J (1992) Medical Mycology. Lea \& Febiger, Philadelphia, $\mathrm{Pa}$.

Lian T, Simmer MI, D’Souza CA, Steen BR, Zuyderduyn SD, Jones SJ, Marra MA, Kronstad JW (2005) Iron-regulated transcription and capsule formation in the fungal pathogen Cryptococcus neoformans. Mol Microbiol 55:1452-1472.

Livak KJ, Schmittgen TD (2001) Analysis of relative gene expression data using real-time quantitative PCR and the 2(-Delta Delta C(T)) Method. Methods 25:402-408.

Ma H, Hagen F, Stekel DJ, Johnston SA, Sionov E, Falk R, Polacheck I, Boekhout T, May RC (2009) The fatal fungal outbreak on Vancouver Island is characterized by enhanced intracellular parasitism driven by mitochondrial regulation. Proc Natl Acad Sci U S A 106:12980-12985.

Ma H, May RC (2010) Mitochondria and the regulation of hypervirulence in the fatal fungal outbreak on Vancouver Island. Virulence 1:197-201.

Ngamskulrungroj P, Price J, Sorrell T, Perfect JR, Meyer W (2011) Cryptococcus gattii virulence composite: candidate genes revealed by microarray analysis of high and less virulent Vancouver island outbreak strains. PLoS One 6:e16076.

Nyhus KJ, Wilborn AT, Jacobson ES (1997) Ferric iron reduction by Cryptococcus neoformans. Infect Immun 65:434-438.

Nyhus KJ, Jacobson ES (1999) Genetic and physiologic characterization of ferric/cupric reductase constitutive mutants of Cryptococcus neoformans. Infect Immun 67:2357-2365.

Pastorian K, Hawel L, Byus CV (2000) Optimization of cDNA representational difference analysis for the identification of differentially expressed mRNAs. Anal Biochem 283:89-98.

Paumi CM, Chuk M, Chevelev I, Stagljar I, Michaelis S (2008) Negative regulation of the yeast $\mathrm{ABC}$ transporter Ycflp by phosphorylation within its N-terminal extension. J Biol Chem 283:27079-27088.

Philpott CC, Protchenko O (2008) Response to iron deprivation in Saccharomyces cerevisiae. Eukaryot Cell 7:20-27.

Pouliot B, Jbel M, Mercier A, Labbé S (2010) abc3+ encodes an iron-regulated vacuolar ABC-type transporter in Schizosaccharomyces pombe. Eukaryot Cell 9:59-73.

Puig S, Askeland E, Thiele DJ (2005) Coordinated remodeling of cellular metabolism during iron deficiency through targeted mRNA degradation. Cell 120:99-110.

Rosa e Silva LK, Staats CC, Goulart LS, Morello LG, Pelegrinelli Fungaro MH, Schrank A, Vainstein MH (2008) Identification of novel temperature-regulated genes in the human pathogen Cryptococcus neoformans using representational difference analysis. Res Microbiol 159:221-229.

Sanguinetti M, Posteraro B, La Sorda M, Torelli R, Fiori B, Santangelo R, Delogu G, Fadda G (2006) Role of AFR1, an $\mathrm{ABC}$ transporter-encoding gene, in the in vivo response to fluconazole and virulence of Cryptococcus neoformans. Infect Immun 74:1352-1359.

Shakoury-Elizeh M, Tiedeman J, Rashford J, Ferea T, Demeter J, Garcia E, Rolfes R, Brown PO, Botstein D, Philpott CC (2004) Transcriptional remodeling in response to iron deprivation in Saccharomyces cerevisiae. Mol Biol Cell 15:1233-1243.

Shakoury-Elizeh M, Protchenko O, Berger A, Cox J, Gable K, Dunn TM, Prinz WA, Bard M, Philpott CC (2010) Meta- 
bolic response to iron deficiency in Saccharomyces cerevisiae. J Biol Chem 285:14823-14833.

Silva MG, Schrank A, Bailão EF, Bailão AM, Borges CL, Staats CC, Parente JA, Pereira M, Salem-Izacc SM, Mendes-Giannini MJ, Oliveira RM, Silva LK, Nosanchuk JD, Vainstein MH, de Almeida Soares CM (2011) The homeostasis of iron, copper, and zinc in paracoccidioides brasiliensis, Cryptococcus neoformans var. grubii, and Cryptococcus gattii: a comparative analysis. Front Microbiol 2:49.

Sorrell TC (2001) Cryptococcus neoformans variety gattii. Med Mycol 39:155-168.
Stephen C, Lester S, Black W, Fyfe M, Raverty S (2002) Multispecies outbreak of cryptococcosis on southern Vancouver Island, British Columbia. Can Vet J 43:792-794.

Sugita M, Sugiura M (1994) The existence of eukaryotic ribonucleoprotein consensus sequence-type RNA-binding proteins in a prokaryote, Synechococcus 6301. Nucleic Acids Res 22:25-31.

Sutak R, Lesuisse E, Tachezy J, Richardson DR (2008) Crusade for iron: iron uptake in unicellular eukaryotes and its significance for virulence. Trends Microbiol 16:261-268.

All the content of the journal, except where otherwise noted, is licensed under a Creative Commons License CC BY-NC. 